PASSOS, S; KAWAKAMI, J; NAZARENO, NRX; SANTOS, KC; TAMANINI JUNIOR, C. 2017. Produtividade de cultivares de batata orgânica em região subtropical do Brasil. Horticultura Brasileira 35: 628-633. DOI - http://dx.doi.org/10.1590/S0102-053620170424

\title{
Produtividade de cultivares de batata orgânica em região subtropical do Brasil
}

\author{
Sara Passos ${ }^{1}$; Jackson Kawakami ${ }^{1}$; Nilceu RX Nazareno²; Keli C Santosi'; Cleto Tamanini Junior ${ }^{1}$ \\ 'Universidade Estadual do Centro-Oeste (UNICENTRO), Guarapuava-PR, Brasil; sarapassos84@gmail.com; jkawakami@unicentro.br; \\ santtos_keli@yahoo.com.br; junior_tamanini@hotmail.com; ${ }^{2}$ Instituto Agronômico do Paraná (IAPAR), Curitiba-PR, Brasil; nilceu@iapar.br
}

\section{RESUMO}

A escolha da cultivar é fundamental para se alcançar altas produtividades de batata em sistema de cultivo orgânico. O objetivo deste trabalho foi avaliar a produtividade e os componentes produtivos de tubérculos e sugerir cultivar de batata para sistema de cultivo orgânico na região Sul do Brasil. O experimento foi realizado em duas safras, 2013/2014 e 2014/2015, três ensaios, em Guarapuava-PR e Caseiros-RS. Foram avaliadas oito cultivares (Agata, Clara, Eliza, Catucha, Aracy Ruiva, Itararé, Vitória e Cris) quanto à produtividade comercial e total de tubérculos, número de tubérculo total e comercial, e porcentagem de massa seca dos tubérculos. O delineamento experimental foi blocos ao acaso em esquema de parcela subdividida, em que os ensaios foram alocados na parcela e as cultivares nas subparcelas, com quatro repetições. A produtividade total e comercial das cultivares variou conforme o ensaio, entretanto 'Catucha' manteve-se sempre no grupo das cultivares mais produtivas, atingindo cerca de 28 e 23 t/ha de produtividade total e comercial, respectivamente. A relativa alta produtividade dessa cultivar foi devido principalmente ao maior número de tubérculos produzidos, cerca de oito e quatro tubérculos/ planta, total e comercial, respectivamente. Além disso, essa cultivar produziu tubérculos com maior porcentagem de massa seca nos três ensaios (25; 16 e $21 \%$ nos ensaios $1 ; 2$ e 3 , respectivamente). Deste modo, 'Catucha' é uma das cultivares sugeridas para o plantio de batata em sistema de cultivo orgânico em regiões de clima subtropical no Brasil.

Palavras-chave: Solanum tuberosum, esterco, rendimento, tubérculo.

\begin{abstract}
Yield of organic potato cultivars in the subtropical region of Brazil

The cultivar selection is fundamental to reach high potato yield in the organic production system. The objective of this work was to evaluate tuber yield and yield components and make suggestion for organic production system in South region of Brazil. The experiment was carried out in two crop seasons, 2013/2014 and 2014/2015, three trials, in Guarapuava, Paraná State and Caseiros, Rio Grande do Sul State, Brazil. Eight cultivars were evaluated (Agata, Clara, Eliza, Catucha, Aracy Ruiva, Itararé, Vitória and Cris) for total and marketable tuber yield, number of total and marketable tubers, and percentage of tuber dry matter content. A completely randomized block design in a split plot scheme, with trials as main plot and cultivars in sub plot, and four replications was used. The total and marketable yield varied according to the trial, however 'Catucha' stayed always in the group of high yielding cultivars, reaching around 28 and $23 \mathrm{t} /$ ha of total and marketable yield, respectively. The relatively high yield of this cultivar was mainly due to high number of tubers, around eight and four/plant, total and marketable tubers, respectively. Moreover, this cultivar had the tubers with higher percentage of tuber dry matter content in all three trials $(25 ; 16$ and $21 \%$ in the trials $1 ; 2$ and 3, respectively). Therefore, 'Catucha' is one of the suggested cultivars for the organic potato system in region of subtropical climate in Brazil.
\end{abstract}

Keywords: Solanum tuberosum, manure, productivity, tubers.

(Recebido para publicação em 23 de junho de 2016; aceito em 28 de agosto de 2017)

(Received on June 23, 2016; accepted on August 28 2017)

$\mathrm{E}_{\mathrm{s}}^{\mathrm{n}}$ $\mathrm{m}$ tempos atuais em que o debate sobre o bem-estar humano e a produção de alimentos aumenta, o cultivo orgânico se destaca como uma prática sustentável (Bennett, 2017). No futuro o cultivo orgânico poderá alcançar maior produtividade que o cultivo convencional, pois o sistema orgânico se relaciona melhor com problemas como degradação do solo, mudanças climáticas e problemas fitossanitários (Azadi et al., 2011). Esse sistema tem como princípio minimizar impactos ao meio ambiente, através da conservação da matéria orgânica do solo e da possibilidade de recuperação de atributos chaves da sustentabilidade do solo (Nelson et al., 2009).

A obtenção de boa produtividade de batata em sistema de cultivo orgânico é um desafio aos produtores, sendo que as informações de manejo e cultivares são escassas (Reichert et al., 2013). A alta produtividade no sistema de cultivo orgânico está relacionada ao manejo da cultura como adubação, controle de pra- gas e doenças e a existência de cultivares adaptadas (Palmer et al., 2013). Esses mesmos autores relatam que o principal fator para alta produtividade no cultivo orgânico de batata é a escolha correta da cultivar, a qual deve ser adaptada ao sistema de cultivo e ao ambiente e apresentar alto potencial produtivo e resistência às principais pragas e doenças (Palmer et al., 2013).

As principais cultivares utilizadas no Brasil, Ágata, Asterix, Markies, Mondial e Atlantic, são importadas, sendo 
adaptadas a ambientes com temperaturas amenas e dias longos (Silva et al., 2009) e ao sistema de cultivo convencional. Há disponibilidade de cultivares selecionadas no Brasil e voltadas para a utilização em cultivo orgânico (Pereira et al., 2001; Nazareno et al., 2015). Entretanto, o cultivo orgânico de batata no Brasil e consequentemente a utilização de cultivares para esse sistema de cultivo ainda é baixo (Leite et al., 2010).

Rossi et al. (2011) estudaram a produtividade de 18 cultivares de batata em sistema orgânico em região de clima tropical de altitude (Monte Alegre do Sul-SP). Esses autores concluíram que as cultivares Itararé, Apuã e Cupido, além dos clones avançados APTA 16.5, APTA 21.54 e IAC 6090 possuem alto potencial produtivo em cultivo orgânico. Zarynska \& Pietrasko (2015) concluíram que a variação de produtividade devido às condições climáticas em cultivares de batata é maior em sistema orgânico comparado ao sistema convencional. Dessa forma, é importante verificar se as cultivares mais produtivas em cultivo orgânico conduzidos em ambiente de clima tropical também são as mais produtivas em ambiente de clima subtropical.

O objetivo desse trabalho foi avaliar a produtividade e os componentes produtivos de cultivares de batata em sistema de cultivo orgânico em região de clima subtropical no Brasil e sugerir cultivares para esses locais.

\section{MATERIAL E MÉTODOS}

Avaliaram-se as cultivares Agata (testemunha), Clara, Eliza, Catucha, Cris, Aracy Ruiva, Vitória e Itararé.

O experimento foi conduzido nos municípios de Guarapuava-PR e Caseiros-RS. Em Guarapuava, conduziram-se os ensaios nas safras das águas de 2013/2014 (ensaio 1) e 2014/2015 (ensaio 3), no campo experimental do Instituto Agronômico do Paraná (IAPAR) (2523'42'S, 51²7'28'O; altitude 1029 m). Em Caseiros conduziu-se o ensaio na safra das águas de 2014/2015 (ensaio 2), em campo nativo na propriedade Recanto (28'26'28'S, 5140'30'O; altitude $763 \mathrm{~m})$.
O delineamento experimental empregado foi blocos ao acaso em esquema de parcela subdividida, em que os ensaios foram considerados como parcela e as cultivares como subparcelas, com quatro repetições. A subparcela foi composta por 6 linhas de $4 \mathrm{~m}$, em espaçamento de $80 \mathrm{~cm}$ entre linhas e $25 \mathrm{~cm}$ entre plantas, com 16 plantas por linha, totalizando 96 plantas por subparcela. Como área útil utilizou-se apenas as 4 linhas centrais, desprezando-se a primeira e última planta de cada linha, resultando em 56 plantas por subparcela.

O preparo do solo foi iniciado cerca de um mês antes do plantio, com uma subsolagem e duas gradagens. Precedendo o plantio, efetuou-se uma gradagem leve com posterior sulcamento da área experimental. Para o fornecimento de nitrogênio, empregou-se a quantidade total de 15 t/ha de cama de aviário e/ou esterco ovino, conforme a recomendação de Souza \& Resende (2003). Não foi necessário aplicar potássio, segundo a análise de solo em nenhum dos 3 ensaios. No ensaio 1, foram utilizados $280 \mathrm{~kg} / \mathrm{ha}$ de fosfato natural, segundo recomendação da Comissão de Química e Fertilidade do Solo do Rio Grande do Sul e Santa Catarina (CQFS-RS/SC, 2004), aplicada na área um mês antes do plantio. Foram utilizados 11,25 t/ ha de cama de aviário e 3,75 t/ha de esterco de ovino, aplicados diretamente no sulco, um dia antes do plantio. $\mathrm{O}$ plantio foi realizado manualmente no dia 15 de novembro de 2013. No en-

Tabela 1. Produtividade total e comercial de tubérculos ( $\mathrm{t} / \mathrm{ha}$ ), número total e comercial de tubérculos (por planta), e porcentagem de massa seca (MS) de tubérculos comerciais de oito cultivares de batata cultivada em sistema orgânico, em três ensaios nas safras 2013/2014 e 2014/2015 total and marketable tuber yield ( $\mathrm{t} / \mathrm{ha}$ ), total and marketable number of tubers (per plant), and percentage of dry matter (MS) of marketable potato tubers of eight cultivars, in organic production system, in three trials, in the growing seasons of 2013/2014 and 2014/2015\}. Guarapuava/Caseiros, UNICENTRO, 2016.

\begin{tabular}{|c|c|c|c|c|c|}
\hline \multirow[t]{2}{*}{ Tratamentos } & \multicolumn{2}{|c|}{ Produtividade (t/ha) } & \multicolumn{2}{|c|}{$\begin{array}{l}\mathrm{N}^{0} \text { de tubérculos } \\
\text { por planta }\end{array}$} & \multirow[t]{2}{*}{ MS (\%) } \\
\hline & Total & Comercial & Total & Comercial & \\
\hline \multicolumn{6}{|l|}{ Ensaio $(\mathbf{E})^{1}$} \\
\hline E1 & 17,2 & 13,5 & 5,8 & 3,1 & 21,1 \\
\hline E2 & 29,6 & 20,5 & 8,4 & 3,7 & 14,7 \\
\hline E3 & 18,3 & 15,2 & 6,0 & 3,3 & 18,4 \\
\hline \multicolumn{6}{|l|}{ Cultivar (C) } \\
\hline Ágata & 23,6 & 16,3 & 6,3 & 3,8 & 14,9 \\
\hline Clara & 22,9 & 19,2 & 4,6 & 3,8 & 18,5 \\
\hline Eliza & 18,9 & 14,9 & 5,7 & 3,0 & 17,8 \\
\hline Catucha & 28,3 & 22,7 & 7,6 & 4,0 & 20,6 \\
\hline Cris & 19,5 & 13,5 & 6,2 & 3,1 & 19,4 \\
\hline A. Ruiva & 17,2 & 12,0 & 5,6 & 2,7 & 18,6 \\
\hline Vitória & 22,0 & 17,5 & 4,9 & 3,4 & 16,7 \\
\hline Itararé & 21,6 & 15,1 & 5,6 & 3,2 & 18,3 \\
\hline $\bar{E}$ & $* * 2$ & $* *$ & $* *$ & $* *$ & $* *$ \\
\hline $\mathrm{C}$ & $* *$ & $* *$ & $* *$ & $* *$ & $* *$ \\
\hline $\mathrm{ExC}$ & $* *$ & $* *$ & $* *$ & $* *$ & $* *$ \\
\hline $\mathrm{CV}(\%) \mathrm{E}$ & 10,6 & 17,6 & 14,9 & 13,1 & 18,9 \\
\hline $\mathrm{CV}(\%) \mathrm{C}$ & 14,0 & 18,6 & 12,1 & 16,0 & 14,3 \\
\hline
\end{tabular}

${ }^{1}$ E1= safra 2013/2014 em Guarapuava-PR (2013/2014 crop season in Guarapuava); E2= safra 2014/2015 em Caseiros-RS (2014/2015 crop season in Caseiros); E3= safra 2014/2015 em Guarapuava-PR (2014/2015 crop season in Guarapuava); ${ }^{2 * *}$ diferença estatística significativa a $\mathrm{p}<0,01$ (statistically significant difference at $\mathrm{p}<0.01$ ). 
saio 2 (2014/2015), aplicou-se calcário dolomítico (PRNT 80\%) na dose de 3,7 $\mathrm{t} / \mathrm{ha}$ devido ao baixo $\mathrm{pH}$ em água $(5,5)$ conforme recomendação da CQFS-RS/ SC (2004), dois meses antes do plantio. Utilizou-se $160 \mathrm{~kg} / \mathrm{ha}$ de termofosfato (Yoorin), fornecido um mês antes do plantio. Para a adubação orgânica foi utilizado 15 t/ha de cama de aviário, também aplicada diretamente no sulco de plantio antes do plantio. Os tubérculos foram plantados manualmente no dia $1^{\circ}$ de novembro de 2014. No ensaio 3, utilizou-se $270 \mathrm{~kg} / \mathrm{ha}$ de fosfato natural e 15 t/ha de esterco de ovino, e os tubérculos foram plantados manualmente no dia 13 de outubro de 2014.

Em todos os ensaios, a amontoa foi realizada manualmente cerca de dez dias após a emergência das plantas. Nenhum tratamento fitossanitário foi realizado para o controle de pragas e doenças. $\mathrm{O}$ controle de plantas daninhas foi realizado por meio da amontoa e, quando necessário, tais plantas foram retiradas manualmente em todas os ensaios.

A colheita dos tubérculos foi realizada cerca de dez dias após a maturação fisiológica das plantas, quando $85 \%$ das hastes estavam secas. Para avaliação da produção, foram coletados tubérculos de 12 plantas por parcela, classificando-os em comercial (tubérculos maiores que $45 \mathrm{~mm}$ de diâmetro) e não comercial (tubérculos menores ou iguais a $45 \mathrm{~mm}$ de diâmetro) por planta, anotando-se o número e a massa fresca e seca. A massa seca foi quantificada após secagem em estufa de aeração forçada $\left(70^{\circ} \mathrm{C}\right)$ até se atingir massa constante. Com os dados de massa fresca e seca dos tubérculos comerciais, calculou-se a porcentagem de massa seca.

Os dados foram submetidos à análise de variância (ANOVA) e quando se identificou diferença estatística significativa, as médias foram comparadas pelo teste de Tukey a $5 \%$ de probabilidade do erro.

\section{RESULTADOS E DISCUSSÃO}

Constatou-se interação significativa para produção total e comercial de tubérculos, número total e comercial de tubérculos e para porcentagem de massa seca de tubérculos (Tabela 1). De modo geral, observa-se que a maior produtividade total foi registrada no ensaio 2 (safra 2014/2015 em Caseiros), porém a ordem das cultivares mais produtivas variou conforme o ensaio (Figura 1a). 'Ágata' esteve no grupo das cultivares mais produtivas nos ensaios 1 (safra 2013/2014 em Guarapuava) e 3 (safra 2014/2015 em Guarapuava), porém ficou no grupo menos produtivo no ensaio 2. Fato semelhante ocorreu com 'Clara', 'Vitória' e 'Itararé'.

Por outro lado, 'Catucha' manteve-se no grupo das cultivares mais produtivas em todos os ensaios. A produtividade total média de tubérculos da cultivar

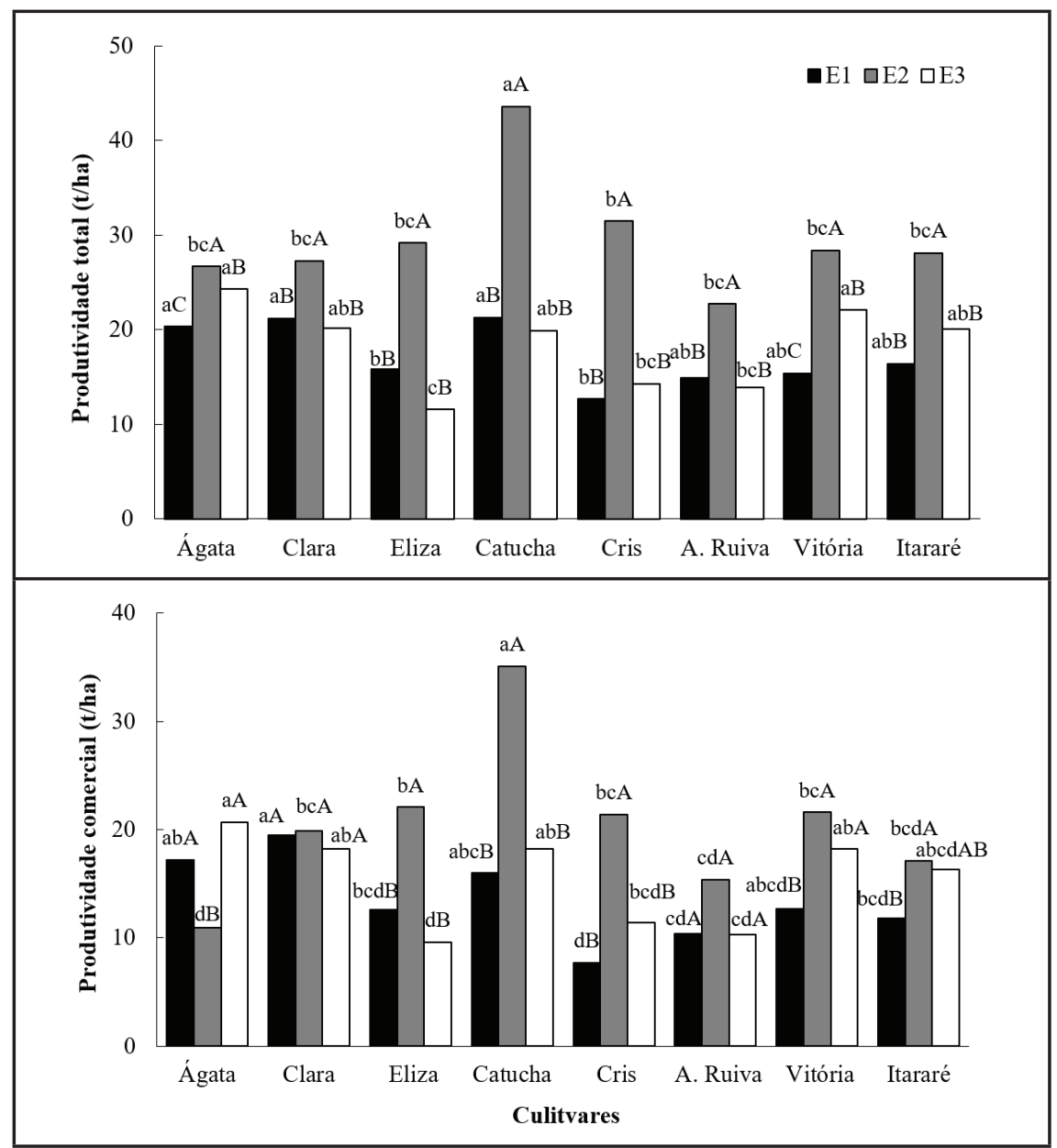

Figura 1. Produtividade (t/ha) total (a) e comercial (b) de tubérculos de oito cultivares de batata em sistema de cultivo orgânico, em três ensaios nas safras 2013/2014 e 2014/2015, em Guarapuava-PR e Caseiros-RS \{total (a) and marketable (b) tuber yield of potato tubers of eight cultivars, in organic production system, in three trials in 2013/2014 and 2014/2015 crop seasons, in Guarapuava and Caseiros \}; Médias seguidas de mesmas letras não diferem estatisticamente entre si pelo teste de Tukey, $5 \%$ (means followed by same letters do not differ statistically from each other, Tukey test, $5 \%$ ); Letras minúsculas comparam as cultivares em um mesmo ensaio e letras maiúsculas comparam os ensaios em uma mesma cultivar (lowercase letters compare the cultivars in the same trial and uppercase letters compare trials on the same cultivar). Guarapuava/Caseiros, UNICENTRO, 2016. 
Virmond et al. (2017), em experimento a campo em sistema de cultivo orgânico no verão, observaram 7 t/ha de produtividade comercial de tubérculos para 'Catucha', sendo essa a cultivar que apresentou o melhor rendimento em relação às outras cultivares estudadas. Algumas cultivares, como Ágata, Clara e Vitória, estavam no grupo das cultivares mais produtivas nos ensaios 1 e 3 , porém esse fato não se repetiu no ensaio 2 , indicando menor estabilidade produtiva dessas cultivares em relação à 'Catucha'. Vale ressaltar que o padrão de classificação de tubérculos adotado para o sistema convencional pode não ser o mais adequado para o sistema de cultivo orgânico, uma vez que os consumidores poderiam aceitar tubérculos de menor tamanho se cultivados sem a utilização de agrotóxicos e fertilizantes minerais (Leite et al., 2010).

O número total de tubérculos produzido pela cultivar Ágata foi superior a seis tubérculos por planta nos diferentes ensaios (Figura 2a). Por outro lado, a cultivar Catucha produziu alta quantidade de tubérculos totais nos ensaios 1 e 2, de sete e nove tubérculos por planta, respectivamente; porém produziu cinco tubérculos por planta no ensaio 3. Estudo de Virmond et al. (2017), analisando o número total de tubérculos por planta em cultivo orgânico também em Guarapuava, obtiveram 12 tubérculos para 'Catucha', 14 para 'Clara', 10 para 'Ágata' e 11 para 'Eliza', que são valores superiores à média dos três ensaios observada no presente trabalho. Contrariamente, Rossi et al. (2011), em cultivo orgânico, em Monte Alegre do Sul-SP, constataram valores similares para as cultivares Catucha e Ágata, mas superiores para A. Ruiva e Itararé.

O número de tubérculos comercias das cultivares variou conforme o ensaio (Figura 2b), comportando-se de maneira similar ao número total de tubérculos, com exceção da 'Ágata'. No ensaio 2, 'Agata' não diferiu da 'Clara', 'Catucha' e 'Cris', que foram as cultivares com maior número total de tubérculos. Porém, em relação ao número comercial de tubérculos, a cultivar Agata teve o menor número de tubérculos juntamente com 'Eliza' e ficou no grupo das cultivares com menor número de tubérculo comerciais. Dessa forma, 'Ágata' apesar de ter sido a cultivar com o maior número total de tubérculos nos três ensaios, não teve maior número de tubérculos comerciais em dois dos três ensaios.

Fatores ambientais e genéticos influenciam na formação e no enchimento de tubérculos (Khan et al., 2014), que por sua vez interferem no número total e comercial de tubérculos. Deste modo, pode-se compreender o menor número de tubérculos comerciais da cultivar Ágata no ensaio 2, que apesar de formar precocemente tubérculos, não conseguiu crescer os tubérculos formados, principalmente no ensaio 2 .

'Ágata' ficou no grupo das cultivares que produziram tubérculos com menor porcentagem de massa seca nos três ensaios, enquanto o oposto foi observado

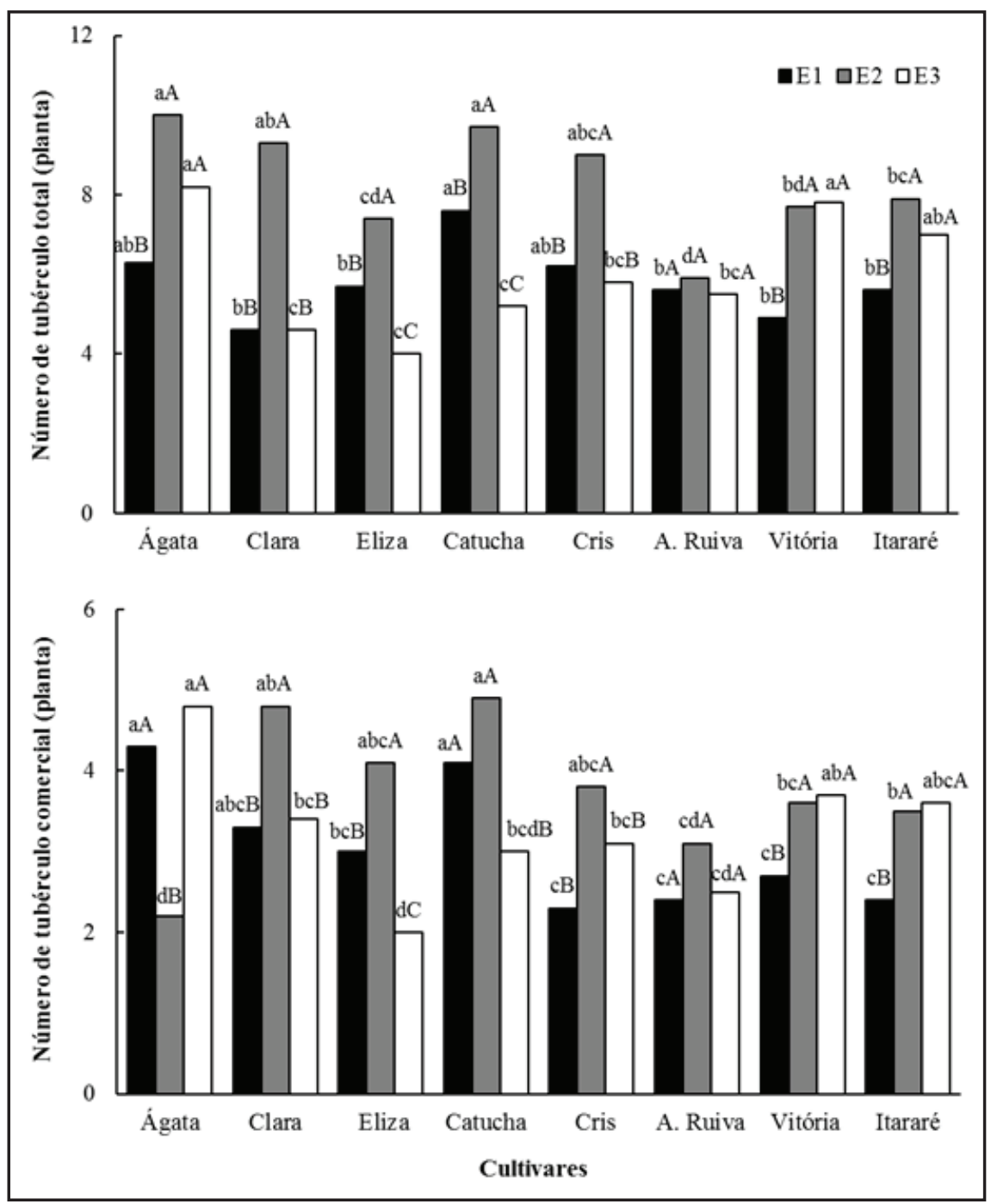

Figura 2. Número de tubérculo total por planta (a) e número de tubérculo comercial por planta (b) de oito cultivares de batata em sistema de cultivo orgânico, em três ensaios nas safras 2013/2014 e 2014/2015, em Guarapuava-PR e Caseiros-RS \{number of total (a) and of marketable tubers per plant (b) of potato tubers of eight cultivars, in organic production system, in three trials in 2013/2014 and 2014/2015 crop seasons, in Guarapuava and Caseiros \}; Médias seguidas de mesmas letras não diferem estatisticamente entre si pelo teste de Tukey, $5 \%$ (means followed by the same letters do not differ statistically from each other, by Tukey test, $5 \%$ ); Letras minúsculas comparam as cultivares em um mesmo ensaio e letras maiúsculas comparam os ensaios em uma mesma cultivar (lowercase letters compare the cultivars in the same trial and uppercase letters compare trials on the same cultivar), E1=safra 2013/2014 em Guarapuava-PR (2013/2014 crop season in Guarapuava); E2= safra 2014/2015 em Caseiros-RS (2014/2015 crop season in Caseiros); E3= safra 2014/2015 em GuarapuavaPR. (2014/2015 crop season in Guarapuava). Guarapuava/Caseiros, UNICENTRO, 2016. 


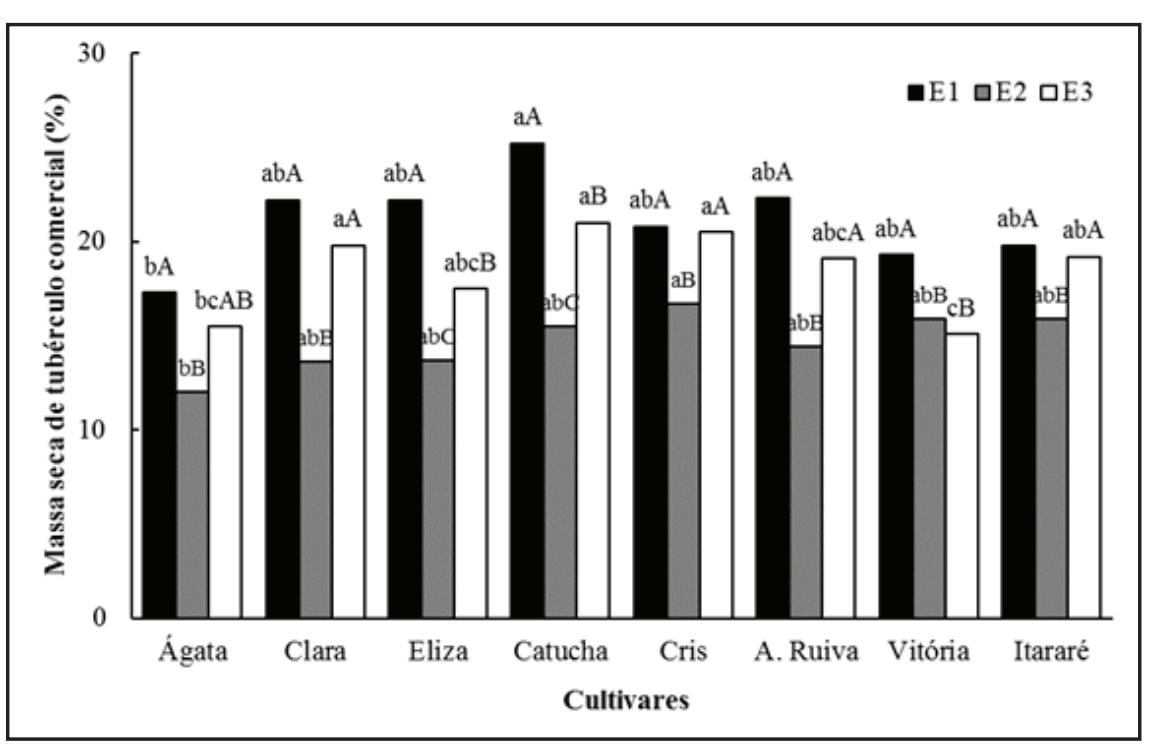

Figura 3. Porcentagem de massa seca de tubérculos de oito cultivares de batata em sistema orgânico, em três ensaios nas safras 2013/2014 e 2014/2015, em Guarapuava-PR e CaseirosRS (percentage of dry weight of potato tuber of eight cultivars, in organic production system, in three trials in 2013/2014 and 2014/2015 crop seasons, in Guarapuava and Caseiros); Médias seguidas de mesmas letras não diferem estatisticamente entre si pelo teste de Tukey, $5 \%$ (means followed by same letters do not differ statistically from each other, Tukey test, $5 \%$ ); Letras minúsculas comparam as cultivares em um mesmo ensaio e letras maiúsculas comparam os ensaios em uma mesma cultivar (lowercase letters compare the cultivars in the same trial and uppercase letters compare trials on the same cultivar); E1= safra 2013/2014 em Guarapuava-PR (2013/2014 crop season in Guarapuava); E2= safra 2014/2015 em Caseiros-RS (2014/2015 crop season in Caseiros); E3= safra 2014/2015 em GuarapuavaPR (2014/2015 crop season in Guarapuava). Guarapuava/Caseiros, UNICENTRO, 2016.

nas cultivares Clara, Eliza, Catucha, Cris, Aracy Ruiva e Itararé, que estiveram no grupo das cultivares com maior porcentagem de massa seca de tubérculos (Figura 3). Os valores observados no presente estudo são semelhantes ao encontrado por Rossi et al. (2011), de $19,16 \%$ para 'Ágata', $24,90 \%$ para 'Catucha', 26,25\% para 'Aracy Ruiva' e $23,60 \%$ para 'Itararé', em sistema de cultivo orgânico. A diferença no acúmulo de massa seca de tubérculos entre as cultivares está relacionada à interação genótipo x ambiente de cultivo (Fernandes et al., 2010; Rossi et al., 2011).

A cultivar Catucha apresentou alto número total e comercial de tubérculos (Figura $2 \mathrm{a}$ e $2 \mathrm{~b}$ ). Isso pode ser devido à formação precoce de tubérculos e ao rápido crescimento de tubérculos. Como essa cultivar produziu uma alta quantidade de tubérculos, houve também uma alta quantidade de tubérculos comerciais, resultando na alta produtividade total e comercial. Silva et al. (2012), em pesquisa de avaliação de diferentes genótipos de batata, relataram que o número e o tamanho de tubérculos influencia diretamente na produtividade de tubérculos comerciais. Os resultados do presente estudo corroboram com Virmond et al. (2017), que relataram maior produtividade da 'Catucha' do que outras cultivares, atribuindo isso ao maior número de folhas e IAF dessa cultivar.

Rossi et al. (2011), estudando 18 genótipos de batata em cultivo orgânico, inclusive 'Ágata', 'Aracy Ruiva', 'Catucha' e 'Itararé' utilizados no presente estudo, observaram ordem diferente de produtividade dessas quatro cultivares. No estudo do referido trabalho observou-se quatro grupos de cultivares quanto à produtividade total, sendo que 'Itararé' figurou no grupo das mais produtivas, 'Aracy Ruiva' no segundo grupo e 'Agata' e 'Catucha' no terceiro grupo (Rossi et al., 2011). Como no presente estudo a ordem das cultivares foi distinta, observa-se que as condições edafoclimáticas possuem grande efeito no desempenho das cultivares em sistema orgânico, corroborando o estudo de Zarynska \& Pietrasko (2015). Dessa forma, concluímos que a recomendação de cultivares de batata para o sistema orgânico deve ser estudada e feita para cada condição edafoclimática específica.

Os resultados obtidos neste trabalho demonstram que a cultivar Catucha destaca-se em produtividade total, comercial e porcentagem de massa seca dos tubérculos em sistema de cultivo orgânico em região de clima subtropical, principalmente devido ao seu alto número de tubérculos. Assim, 'Catucha' é a cultivar sugerida para o plantio orgânico em regiões de clima subtropical do Brasil.

\section{REFERÊNCIAS}

AZADI, H; SCHOONBEEK, S; MAHMOUDI, H; DERUDDER, B; MAEYER, PD; WITLOX, F. 2011. Organic agriculture and sustainable food production system: Main potentials. Agriculture, Ecosystems \& Environment 144: 92-94.

BENNETT, EM. 2017. Changing the agriculture and environment conversation. Nature Ecology \& Evolution 1: 1-2. (Article number 0018)

CQFS-RS/SC. 2004. Manual de adubação e calagem para os Estados do Rio Grande do Sul e de Santa Catarina. Porto Alegre: SBCS - Núcleo Regional Sul/UFRGS. 400p.

FERNANDES, AM; SORATTO, RP; SILVA, BL; SCHLICK, GDS. 2010. Crescimento, acúmulo e distribuição de matéria seca em cultivares de batata na safra de inverno. Pesquisa Agropecuária Brasileira 45: 826-835.

KHAN, MS; YIN, X; PUTTEN, PEL; STRUIK, PC. 2014. An ecophysiological model analysis of yield differences within a set of contrasting cultivars and an F1 segregating population of potato (Solanum tuberosum L.) grown under diverse environments. Ecological Modelling 290: 146-154.

LEITE, CD; CARDOSO, F; MARQUES, MI; KAWAKAMI, J; FÁVARO, JL. 2010. Produtos orgânicos: conhecimento da população de Guarapuava, PR. In: Seminário Nacional de Meio Ambiente e Extensão Universitária, I, Anais... Marechal Cândido Rondon: Unioeste. p. 1-6.

NAZARENO, NRX; PEREIRA, AS; SILVA, GO; CASTRO, CM; BERTONCINI, O; MEDEIROS, CAB; HIRANO, E; GOMES, CB; CAMPOS, JF. 2015. IPR-CRIS: Cultivar rústica de batata.Horticultura Brasileira 33: 404-408.

NELSON, KL; LYNCH, DH; BOITEAU, G. 2009. Assessment of changes in soil health throughout organic potato rotation sequences. Agriculture, Ecosystems \& Environment 131: 220-228. 
PALMER, MW; COOPER, J; TÉTARDJONES, C; SREDNICKA-TOBER, D; ARANSKI, M; EYRE, M; SHOTTON, PN; VOLAKAKIS, N; OZTURK, ICL; LEIFERT, C; WILCOCKSON, SJ; BILSBORROW, PE. 2013. The influence of organic and conventional fertilization and crop protection practices, preceding crop, harvest year and weather conditions on yield and quality of potato (Solanum tuberosum) in a long-term management trial. European Journal of Agronomy 49: 83-92.

PEREIRA, AS; COSTA, DM; DANIELS, J; VENDRUSCOLO, JLS; FORTES, GRL; BERTONCINI, O; HIRANO, E; CHOER, E; Augustin, E; GOMES, CB. 2001. BRS Eliza: cultivar de batata para mesa, com película lisa e resistência a doenças. Horticultura Brasileira 19: 258-259.

PERUCH, LAM; SILVA, ACF. 2009. SCS 365
Cota: Primeira cultivar catarinense de batata registrada para o sistema de cultivo orgânico. Revista Brasileira de Agroecologia 4: 31753179.

REICHERT, LJ; GOMES, MC; SCHWENGBER, JE; PEREIRA, AS. 2013. Avaliação de sistemas de produção de batata orgânica na região Sul do Rio Grande do Sul. Horticultura Brasileira 31: 220-230.

ROSSI, F; MELO, PCT; AZEVEDO, JAF; AMBROSANO, EJ; GUIRADO, N; SCHAMMASS, EA; CAMARGO, LF. 2011. Cultivares de batata para sistemas de cultivos orgânicos de produção. Horticultura Brasileira 29: 372-376.

SILVA, FL; PINTO, CABP; ALVES, JD; BENITES, FRG; ANDRADE, CM; BHERING, LL. 2009. Caracterização morfofisiológica de clones precoces e tardios de batata visando à adaptação a condições tropicais. Bragantia 68: 295-302.

SILVA, GO; CASTRO, CM; TERRES, LR; ROHR, A; SUINAGA, FA; PEREIRA, AS. 2012. Componentes de produção, ciclo vegetativo e peso específico de clones de batata. Horticultura Brasileira30: 557-560.

SOUZA, JL; RESENDE, P. Manual de Horticultura Orgânica. 2003. Viçosa: Aprenda Fácil Editora, 564p.

VIRMOND, EP; KAWAKAMI, J; SOUZA DIAS, JAC. 2017. Seed-potato production through sprouts and field multiplication and cultivar performance in organic system. Horticultura Brasileira 35: 335-342.

ZARZYŃSKA，K; PIETRASZKO, M. 2015. Influence of climatic conditions on development and yield of potato plants growing under organic and conventional systems in Poland. American Journal of Potato Research 92: 511-517 